\title{
Perception of daily cigarette consumption in the office environment
}

\author{
DAVID A. STERLING and D. J. MOSCHANDREAS \\ IIT Research Institute, Chicago, Illinois
}

and

\author{
ROBERT D. GIBBONS \\ University of Illinois, Chicago, Illinois
}

\section{(Charles W. Eriksen, Sponsor)}

\begin{abstract}
A study was undertaken to investigate how closely smokers and nonsmokers agree in their perception of the number of cigarettes smoked. Information was collected by means of a self-report comfort and environment questionnaire. A secondary objective of the study was to determine whether repeated application of the same questionnaire had any effect on the responses over time. The information obtained from 163 respondents in 49 office work areas shows that nonsmokers perceived the number of cigarettes smoked within their office work areas as significantly lower than either the number perceived or the number reported consumed by smokers. There were no significant differences, however, between smokers' perceptions of cigarette consumption and their reported consumption. Repeated application of the same questionnaire, or sensitization, had no effect on either the smokers or nonsmokers and their perceived frequency of smoking.
\end{abstract}

One-time self-report questionnaires that rely on an individual's ability to recall an event are used widely to assess exposure to cigarette smoke. Asking people to recall the number of cigarettes that they have smoked or that others have smoked near them seems, at first, a reasonable approach. However, many researchers (Hay \& Foster, 1984; Jackson \& Beaglehole, 1985; National Research Council, 1981; Repace, 1983; Todd, 1978; Warner, 1978) have reported discrepancies in reported consumption when reports are obtained through questionnaire surveys of smokers.

It has been suggested that cigarette smokers, when requested to respond to questions concerning smoking habits, underestimate their cigarette consumption (National Research Council, 1981; Warner, 1978). Much of the discrepancy may be due to the tendency of respondents to underreport behavior or events that may be considered socially undesirable (in this case, smoking). Similarly, nonsmokers may overreport what they consider to be undesirable behavior in others (smoking). In addition, smokers and nonsmokers may differ in their general level of awareness of smoking and therefore may perceive smoking incidence differently. For example, a smoker may underestimate the number of cigarettes smoked because, to him/her, it is a habit; a nonsmoker, however, may overestimate because of a heightened sensitivity to the visibility and irritating effects of tobacco smoke.

Address correspondence to David A. Sterling, Program in Environmental Health, Old Dominion University, Norfolk, VA 23508.
A field study was performed to address two questions: (1) Do self-reports agree on the number of cigarettes smoked as reported by the actual smoker, exposed nonsmokers, and smokers who report the number of cigarettes smoked by other smokers? (2) Do these perceived numbers vary with repeated questioning? The study was designed and performed to measure, both daily and weekly, a subject's recall and perception of environmental conditions and smoking habits.

\section{METHOD}

\footnotetext{
The actual type of work performed (i.e., clerical, professional, or managerial) and the type of building were not controlled for. Four criteria were used in the selection of study sites: (1) smoking was allowed within the working area, (2) most of the work day was spent in the work area, (3) the participants were expected to be at work during the survey week (i.e., no planned vacation or field assignments for that week), and (4) individuals in the work area were willing to participate in a comfort and environmental perception study. A work area was defined as the work space where 2 or more people spend the largest portion of their time in performing the primary activities of their jobs.

Researchers began the study by visiting each work area to collect relevant information regarding each site, to discuss the objectives of the program, and to answer questions by potential participants. No indication was given at any time that the study addressed smoking habits and exposure to environmental tobacco smoke. Potential participants knew that they would be responding to a comfort and environment survey, but were not told when the project would begin.

Researchers made frequent site visits after the study began to see that the criteria were still being met. All participants were supplied with the same instructions. In each building, project representatives distributed and collected completed forms daily. This procedure guaranteed that participants answered daily and did not have the opportunity to refer to their answers from the previous day.
} 
The questionnaire used is shown in Figure 1. Each subject in each work area completed the same questionnaire at the end of each of 7 different work days, in three stages: Stage 1 -on a Friday without any previous warning (response 1), Stage 2-each day of the week immediately following Stage 1 (responses 2-6), and Stage 3-2 weeks after first filling out the questionnaire (response 7).

\section{DATA ANALYSIS}

Three parameters-smokers' perception of cigarette consumption (SP), smokers' reported cigarette consumption (SR), and nonsmokers' perception of cigarette con-

\section{IIT RESEARCH INSTITUTE}

\section{CONFORT AND ENVIRONOAENT PERCEPTION SURVEY}

- Please respona to All Questions as accurately as possible.

- Your answers should describe your designated work area.

THIS IS A RESEARCH STUDY - ALL DATA ARE CONFIDENTIAL.

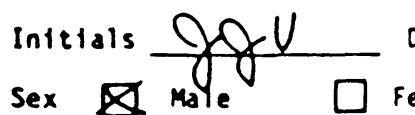

Date

$12-20$

Time $4: 55$

Sex $\square$ male $\square$ remale

Age $\square$ Less than 20

$20-29$

D 30-39

40 or more

Please rate each of the following conditions for your primary work area.

circle the number for each pair of terms below which best describes how you perceive your work area today. The higher the number the better the condition. For example, the answer given below indicated that today you sometimes perceived your designated work area as being too crowded:

$$
\text { Worst } \longrightarrow \text { Best } \longleftrightarrow \text { Worst }
$$

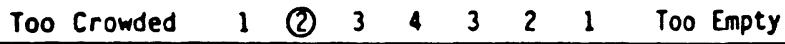

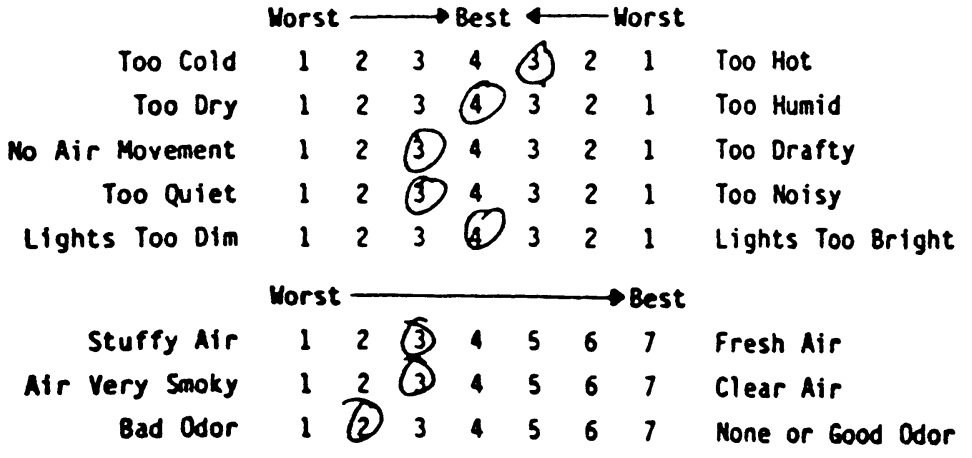

If odor present please specify type

Please answer the following questions.

How many cigarettes were smoked in your primary work area today?

How many hours were you away from your work area on añother work assignment or breaks?

How would you rate the overall comfort of your work area on a scale of 1 to 7 ; from extremely uncomf ortable $D$ to extremely comfortable []?

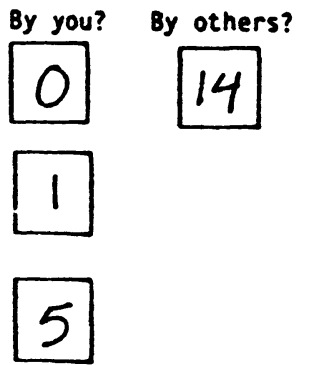

108833

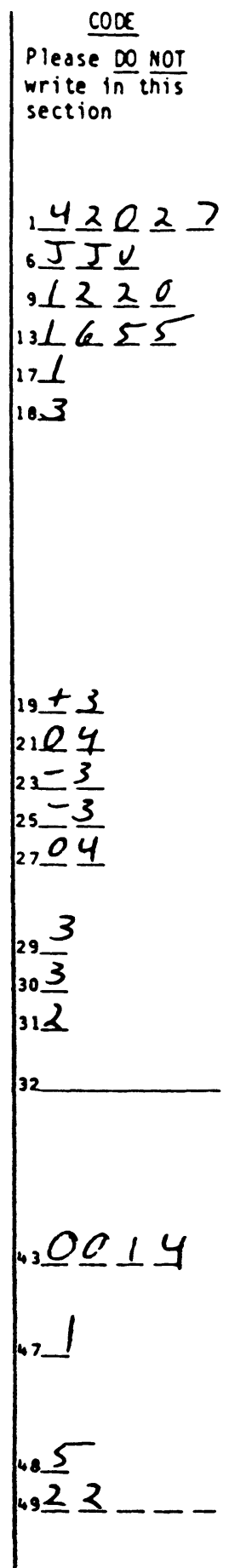

Figure 1. Sample of a comfort and environment perception survey. 
sumption (NSP)-were selected to represent perception of smoking incidence within each working area.

$$
\begin{gathered}
\mathrm{SP}=\frac{\sum_{i=1}^{n}\left(X_{i}+Y_{i}\right)}{n}, \\
\mathrm{SR}=\sum_{i=1}^{n} Y_{i}, \\
\mathrm{NSP}=\frac{\sum_{j=1}^{k} X_{j}}{k},
\end{gathered}
$$

where $X=$ the number of perceived cigarettes smoked by others, $Y=$ the number of cigarettes reported smoked by the subject, $i=i^{\text {th }}$ smoker in the work area, $n=$ total number of smokers in the work area, $j=j^{\text {th }}$ nonsmoker in the work area, and $k=$ total number of nonsmokers in the work area.

Since each person spent different periods of time away from the work area, weighted hourly cigarette consumption values were also determined. For each person, the total time spent within the work area (the period covered by the questionnaire responses) was calculated as the difference between the time when the questionnaire was completed (from an assumed work start time of 8 a.m.) and the time spent away from the work area, as indicated in that person's questionnaire response. For the weighted hourly rate values for SP, SR, and NSP, each person's reported number is divided by the number of hours calculated as being spent within the work area.

A three-factor, mixed-model analysis of variance (SPSS, 1985; Winer, 1970) was used to determine the main effect of time (increased sensitization to the smoking questions with repeated application from Day 1 through Day 7), the main effect of the smoking group (smoker vs. nonsmoker), and the smoking group $\times$ time interaction in terms of (1) smokers' and nonsmokers' perception of cigarette consumption in a work area, (2) nonsmokers' perception and the number of cigarettes smoked as reported by smokers in a work area, and (3) smokers' perceptions and self-reported number of cigarettes smoked by smokers in a work area.

\section{RESULTS}

The data base consisted of 49 work areas with 163 participants (Table 1). Based on statistical power tables

Table 1

Total Study Sample Size and Sample Size of Analyzed Data*

\begin{tabular}{lcccc}
\hline & Work & \multicolumn{3}{c}{ Participants } \\
\cline { 3 - 5 } & Areas & Smokers & Nonsmokers & Total \\
\hline Total sample size $\dagger$ & 58 & 69 & 158 & 227 \\
$\begin{array}{l}\text { Number in which response } \\
\text { sufficient for analysis }\end{array}$ & 49 & 67 & 96 & 163 \\
$\begin{array}{l}\text { in smoking work areas } \\
\begin{array}{l}\text { Percent response from } \\
\text { smoking work area sample }\end{array}\end{array}$ & 100 & 97 & 74 & 82 \\
\hline
\end{tabular}

* Sample size of analyzed data based on proper questionnaire response. †Includes work areas in which smoking was allowed but no smokers were present.
(Winer, 1970) for 50 work areas and 150 people, a false negative rate of less than $20 \%$ (i.e., power $=0.8$ ), a false positive rate of less than $5 \%$, and an effect size of onehalf a standard deviation unit are expected. The sample size obtained complies with the sample size considered appropriate.

The overall participant response rate was $82 \%$ of the sample population. The response rate to the smoking questions differed between smokers $(97 \%)$ and nonsmokers $(74 \%)$.

The sex and age distribution of the study population is shown in Table 2 . Eighty percent of the study population was 30 years of age or older. Males constituted $31 \%$ of the population, females $69 \%$. Of the study population, $41 \%$ were smokers, and, of these, $19 \%$ were male and $81 \%$ female. The remainder of the population, $59 \%$, were nonsmokers, $40 \%$ male and $60 \%$ female.

\section{Nonsmokers' Perception and Smokers' Reported Consumption}

A significant difference was found between nonsmokers' perception of the number of cigarettes smoked and the number of cigarettes reported smoked by smokers. The difference applied to both daily rates $[F(1,516)=$ $52.95, p<.0001]$ and hourly rates $[F(1,516)=46.60$, $p<.0001]$. The number of cigarettes perceived by nonsmokers was significantly lower than the number that smokers reported they had smoked. The mean hourly rate of cigarette consumption per smoker as perceived by nonsmokers was 2.2, and the rate reported by smokers was 2.9 .

The group $\times$ time interaction (effect of repeated application) was not significant for either daily or hourly rates $[F(6,516)=.79, p<.578$, and $F(6,516)=.79$, $p<.579$, respectively]. We can therefore assume that the difference between smokers and nonsmokers for each questionnaire day (over time) was statistically consistent.

\section{Smokers' and Nonsmokers' Perception}

The number of cigarettes smoked as perceived by smokers and nonsmokers was significantly different both for daily rates $[F(1,454)=29.78, p<.0001]$ and for hourly rates $[F(1,454)=25.22, p<.0001]$. The number of cigarettes smoked as perceived by nonsmokers was significantly lower than that perceived by smokers. The mean perceived hourly rate of consumption per smoker was 2.2 by nonsmokers and 2.5 by smokers.

The group $\times$ time interaction was not significant for daily rates $[F(6,454)=0.39, p<.888]$ or for hourly rates $[F(6,454)=0.61, p<.723]$, indicating again that the difference between smokers and nonsmokers was consistent over time.

\section{Smokers' Perception and Reported Consumption}

No statistically significant main effect or interaction was found for either daily or hourly rates for the difference between the number of cigarettes smoked per smoker as perceived by smokers (hourly rate of 2.5 ) and the number of cigarettes reported consumed per smoker by the smokers (hourly rate of 2.9). 
Table 2

Sex and Age Group Distribution by Smoking Category

\begin{tabular}{|c|c|c|c|c|c|}
\hline \multirow[b]{2}{*}{ Age Group } & \multicolumn{2}{|c|}{ Males $(n=51)$} & \multicolumn{2}{|c|}{ Females $(n=112)$} & \multirow{2}{*}{$\begin{array}{c}\text { Total by } \\
\text { Age }(N=163)\end{array}$} \\
\hline & Smokers & Nonsmokers & Smokers & Nonsmokers & \\
\hline$<20$ & 0 & 1 & 1 & 0 & 2 \\
\hline $20-29$ & 2 & 6 & 10 & 13 & 31 \\
\hline $30-39$ & 4 & 14 & 25 & 25 & 68 \\
\hline $40+$ & 7 & 17 & 17 & 19 & 60 \\
\hline Unknown & 0 & 0 & 1 & 1 & 2 \\
\hline Total & 13 & 38 & 54 & 58 & \\
\hline
\end{tabular}

\section{DISCUSSION}

The study was based on the premises that (1) nonsmokers may overreport the number of cigarettes that they perceive being smoked around them and (2) cigarette consumption would be reported more accurately if participants could be sensitized to the study questions with repeated daily use of the questionnaire.

Testing of the first premise showed a statistically significant difference between the number of cigarettes smoked as perceived by nonsmokers and both the perception and the reported consumption of smokers. The number of cigarettes nonsmokers perceived were being smoked within their work area was significantly lower than the number smokers perceived or the number smokers reported they had consumed.

It was expected that nonsmokers would be more responsive to the smoking questions and would perceive a greater frequency of cigarette smoking than smokers and that smokers would underreport. However, only $74 \%$ of all nonsmokers responded to the smoking question, whereas $97 \%$ of all smokers responded. The nonsmokers who responded would be expected to have been more environmentally "aware" and sensitive to those smoking near them than nonsmokers who did not respond. The lower smoking frequency perceived by nonsmokers in this study sample may indicate less concern with the issue of environmental tobacco smoke than is generally assumed.

Smokers' perception of smoking was not significantly different from their reported consumption rate. This suggests that the overall perception of smokers is consistent with their own reported smoking habits.

The calculated number of cigarettes smoked per hour (between two and three cigarettes per smoker per hour) and the percentage of smokers in the study sample (41\%) are higher than the values typically assumed from census data: two cigarettes smoked per smoker per hour (Repace, 1983 ) and $33 \%$ of the population smokes (National Research Council, 1981). This may be explained by the study's focus on work areas in which smoking was allowed and smokers were present, and the high response rate of smokers to the questionnaire.

Testing of the second premise showed that sensitization (repeated application of the questionnaire over a short time period) had no signifi- cant effect on the overall response of either smokers or nonsmokers, or on the difference between the group responses. Researchers, therefore, may use one-time self-report survey studies to obtain consistent information on smoking habits. However, they cannot assume that selfreport responses to one-time questionnaires are accurate until further validation is performed.

\section{REFERENCES}

HAY, D. R., \& Foster, F. H. (1984). Intercensal trends in cigarette smoking in New Zealand:1. Age, sex, and ethnic status. New Zealand Medical Journal, 97(755), 283-285.

JACKSON, R., \& BEAGLEHOLE, R. (1985). Secular trends in underreporting of cigarette consumption. American Journal of Epidemiology, 122(2), 341-344.

National Research Council. (1981). Indoor Pollutants (pp. 149168). Washington, DC: National Academy Press.

RePACE, J. L. (1983). Effects of ventilation on passive smoking risk in a model workspace. Proceedings of an Engineering Foundation Conference on Management of Atmosphere in Tightly Enclosed Spaces. Atlanta, GA: American Society of Heating, Refrigerating and Air Conditioning Engineers.

SPSS, INC. (1985). Statistical Package for the Social Sciences (SPSS/PC+). Chicago, IL:Author

ToDD, G. F. (1978). Cigarette consumption per adult of each sex in various countries. Journal of Epidemiology \& Community Health, 32, 289-293.

Warner, K. E. (1978). Possible increases in the underreporting of cigarette consumption. Journal of the American Statistical Association, 73, 314-318.

WINER, J. (1970). Statistical power analysis for the behavioral sciences. New York: Academic Press.

(Manuscript received for publication July 13, 1987.) 